\title{
AN INTERDISCIPLINARY APPROACH FOR THE EXPERIMENTAL ASSESSMENT OF THE SEISMIC SAFETY OF ARTWORKS
}

\author{
ALESSIA DI MARTINO ${ }^{1}$, GIUSEPPE COCUZZA AVELLINO ${ }^{1}$, EMANUELA \\ PATERNÒ $^{1}$, FRANCESCO CANNIZZARO ${ }^{1 *}$, IVO CALIÒ ${ }^{1}$, GIANFRANCO \\ GIANFRIDDO $^{1}$, RITA VALENTI ${ }^{1}$ AND NICOLA IMPOLLONIA ${ }^{1}$ \\ ${ }^{1}$ Department of Civil Engineering and Architecture (DICAR) \\ University of Catania \\ Viale Andrea Doria 64, 95125 Catania, Italy \\ e-mail: alessiadimartino@alice.it, giuseppe.cocuzzaavellino@unict.it, patermanu@hotmail.it, \\ francesco.cannizzaro@unict.it, ivo.calio@unict.it, ggianfrid@unict.it,rvalenti@unict.it, \\ nicola.impollonia@unict.itwww.dicar.unict.it (*corresponding author)
}

Keywords: Rigid block, Seismic vulnerability, Shaking table, Scale effect, Nonlinear dynamics, Digital model

\footnotetext{
Abstract. Recent seismic events occurred in areas rich of ancient remains and full of cultural and artistic heritage in terms of artworks. Earthquakes may damage buildings, but the vibrations may also induce the uplift and overturning of their content, implying irreparable loss of cultural values. The seismic assessment of objects is usually tackled modelling them as rigid blocks. This paper focuses on statues, which generally present a very complicated geometry, and proposes a general methodology involving different disciplines, for their experimental seismic assessment. The methodology is here applied to the masterpiece of "Paolo Orsi" museum in Syracuse (Italy), that is the "Venere Landolina". Due to the complexity of statues, traditional techniques cannot be considered reliable for a proper geometry reconstruction; therefore, Terrestrial Laser Scanner (TLS) and Unmanned Aerial System (UAS) technologies are here employed to obtain a highly detailed and complete digital model. Aiming at providing a low-cost scaled physical model of the statue, a wooden specimen has been arranged employing a Computer Numerical Control (CNC) milling machine, cutting off disks from flat panels which are then superimposed and glued, progressively reconstructing the actual geometry of the statue. The specimen, able to approximately reproduce the scaled actual geometry, was then tested on a shaking table with ground motions compatible with those expected for the site where the statue is located. The obtained results are finally correlated with those expected for the real scale statue.
} 


\section{INTRODUCTION}

The seismic assessment and protection of the content of buildings represents a challenge of modern engineering; it is relevant in two main cases, that is machinery located inside strategic buildings (e.g. hospitals, control towers) which have to keep their operability in the earthquake aftermath, and artworks whose damage would imply a significant cultural economic and social loss. It is reasonable to consider such objects as lightweight bodies.

In the context of the seismic protection of artworks, the crisis of the material is encountered only in few cases, for which FE models are usually employed, mainly to study and interpret the presence of cracks in statues in static [1] and dynamic [2] conditions. Such objects mostly tend to get damaged not so much for material crisis as for their uplift and the subsequent overturning. For this reason, there is a broad literature aiming at a proper modelling of such systems in seismic conditions; most of these models are based on the rigid body motion [3]-[10], which is governed by nonlinear differential equation. Even in the case of simplified geometry the rigid body motion is difficult to be modelled because of the impairments in the contacts with the base [11] and due to the chaotic character of the rigid body motion [12]. Analogous studies on geometrically complex objects are rarely considered [13] since the governing equations are further complicated; moreover, experimental studies in such cases are prohibitive due to the difficulty to faithfully reproduce specimens consistent with the original model in the laboratory. The interest towards the seismic protection of artworks has been growing in the last decades. Some masterpieces, such as Michelangelo's

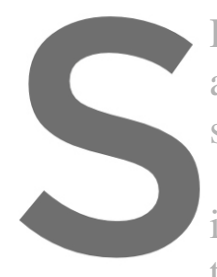
David [1], the "Juno's fountain" [2] and the "Bronzi di Riace"
and in the latter case their seismic protection is assured by a bal
studies concerning the seismic isolation of lightweight objects
The study presented in this paper is focused on stat
interdisciplinary approach for the experimental assessment technology and structural skitls. The proposed methodology is applied to the "Venere ", underwent detailed studies,
1 system isolation [14]. Other
can be found in [15]. [16].
tues, and presents a noyel
of statues Involving suryey,
y is applied to the "Venere

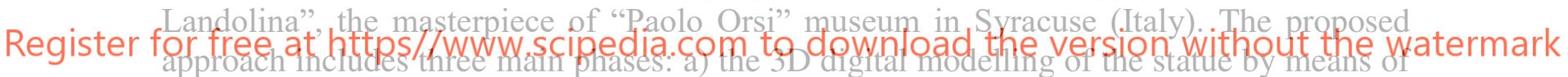

UAS and TLS technologies, b) the reconstruction of a scaled wooden model created with a CNC milling machine based on the digital model, c) the experimental campaign conducted with the application of ground motions compatible with the design spectrum by means of a shaking table, the interpretation of the results, and the correlation with the actual geometry of the statue. The three phases of the proposed methodology are briefly elucidated and then applied to the chosen case study, showing its applicability to other meaningful artworks.

\section{SEISMIC PROTECTION OF ARTWORKS: THE CASE OF THE "VENERE LANDOLINA" IN "PAOLO ORSI" MUSEUM}

The proposed methodology aims at the assessment of the seismic safety of lightweight objects. In the context of artworks, former studies were conducted oriented to their seismic protection. Some of them are oriented to describe the main mitigation strategies [17], some others are detailed studies of statues. In the case of the "Bronzi di Riace" a low invasive semi-passive isolation system (based on a ball system with dissipative wires) on a marble base was devised [14]. In the case of Michelangelo's David, a detailed FEM study was conducted to verify the riskiness associated to cracks observed on one of the legs [1]. 
In the following sections a novel methodology for the seismic assessment of statues involving an experimental campaign on a scaled specimen, reconstructed with a faithful geometry, is proposed. The proposed methodology includes three phases which are summarized in Figure 1. All the considered phases require the adoption of advanced hardware and software tools. The stages of the proposed strategy can be summarized in a knowledge phase, a prototyping phase and the seismic assessment. The knowledge phase consists in a non-invasive geometric scanning of the statue (see section 3 for details) and the manipulation of the output of the survey providing a photorealistic digital model of the statue. In the prototyping phase the solid model is further processed, and a $3 \mathrm{D}$ digital prototype is elaborated; the obtained simplified model represents the input to create a scaled physical counterpart, by superimposing of wooden disks shaped with a Computer Numerical Control machine (see section 4 for details). Finally, the physical prototype is tested on a shaking table considering ground motions compatible with the design spectrum and duly modified to account for the scale factor of the specimen; the results obtained by experimental campaign are elaborated with a tracking motion software and interpreted with the aim of rating the safety of the statue (see section 5 for details).

The conceived methodology is here applied to a meaningful case study selected in the archeological museum "Paolo Orsi" in Syracuse (Italy). Specifically, the "Venere Landolina", that is the masterpiece of the museum, is considered, Figure 2. The marble structure goes back to the II century A.D. and is probably a copy of a former greek statue; its name is related to Saverio Landolina, the archeologist who discovered the Venere in 1804 . This artefact was
selected for its artistic relevance, but also for some geometric features which nake this case
study particularly meaningful. The statye is quite slender, which makes it keen to the uplift, and
is also irregular since the position of the center of gravity is not centercd with respect to the
base. In the first colurnn of Figure 1 the main steps of the proposed methodology applied to the
Venere Landolina aredepicted where the physical model and the intermediated stages of the

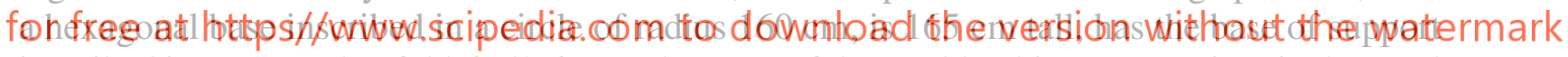
inscribed in a rectangle of $55,6 \times 50,6 \mathrm{~cm}$. The mass of the marble object, approximatively equal to $430 \mathrm{~kg}$, is estimated considering a volume of $162098.79 \mathrm{~cm}^{3}$ and a specific weight equal to $\rho=0.00265 \mathrm{~kg} / \mathrm{cm}^{3}$.

\section{3D DIGITAL MODELLING OF THE STATUE}

The present study establishes a synergy between the teaching and research methodologies and between technological innovation and operational technologies of the specific subject areas, in particular, surveying and data processing and communication.

It is important to develop digital integrated strategies in order to obtain an efficient performance of all the research indicators. In general, the study wants to provide the scientific community with an operational protocol for the virtual rendering of artistic and museum objects [18]. In particular, 3D modelling aims to the development of a physical model for the seismic evaluation of sculptures. In this regard, 3D computer graphics gives an immediate perception of reality less affected by discretization modalities than traditional drawing.

The implementation of software which can transform data coming from TLS, UAS technologies and photogrammetry into 3D models allows the visualization and 3D printing 
Alessia Di Martino, Giuseppe Cocuzza Avellino, Emanuela Paternò, Francesco Cannizzaro, Ivo Caliò,

Gianfranco Gianfriddo, Rita Valenti and Nicola Impollonia

concretisation of artistic objects characterised by sinuous geometric shapes. The present experimental work on "Venere Landolina" has been conducted with the innovative technological instruments of the Laboratory of Representation, SDS of Architecture, University of Catania.

\section{SURVEY}

Features: Laser scanner survey: execution of several scans with TLS technology from different angles to reconstruct the entire geometry of the object. A dense point cloud is obtained as output.

Photogrammetric survey: photos taken through UAS technology and camera to capture images of the object at different heights.

Equipment: • Laser scanner Leica C10.

- SAPR DJI Spark.

- High Resolution Camera Nikon D3200.

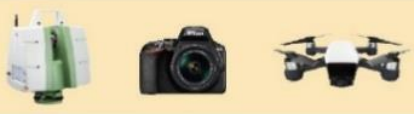

\section{D DIGITAL MODELLINC}

Features: Point cloud obtained via combination and alignment of the data acquired with TLS and UAS technologies. 3D polygonal mesh obtained from the point cloud and subsequent mesh optimization.

Software Cyclone, 3DF Zephyr, Geomagic Wrap, Rhinoceros 5.

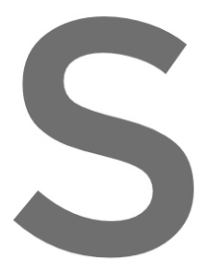

DIGITAL MODEL SEMPLIFICATION

Register for free at https//www.scipedia.com to downiloted the version without the watermark

Equipment: Computer Numerical Control (CNC) milling machine.

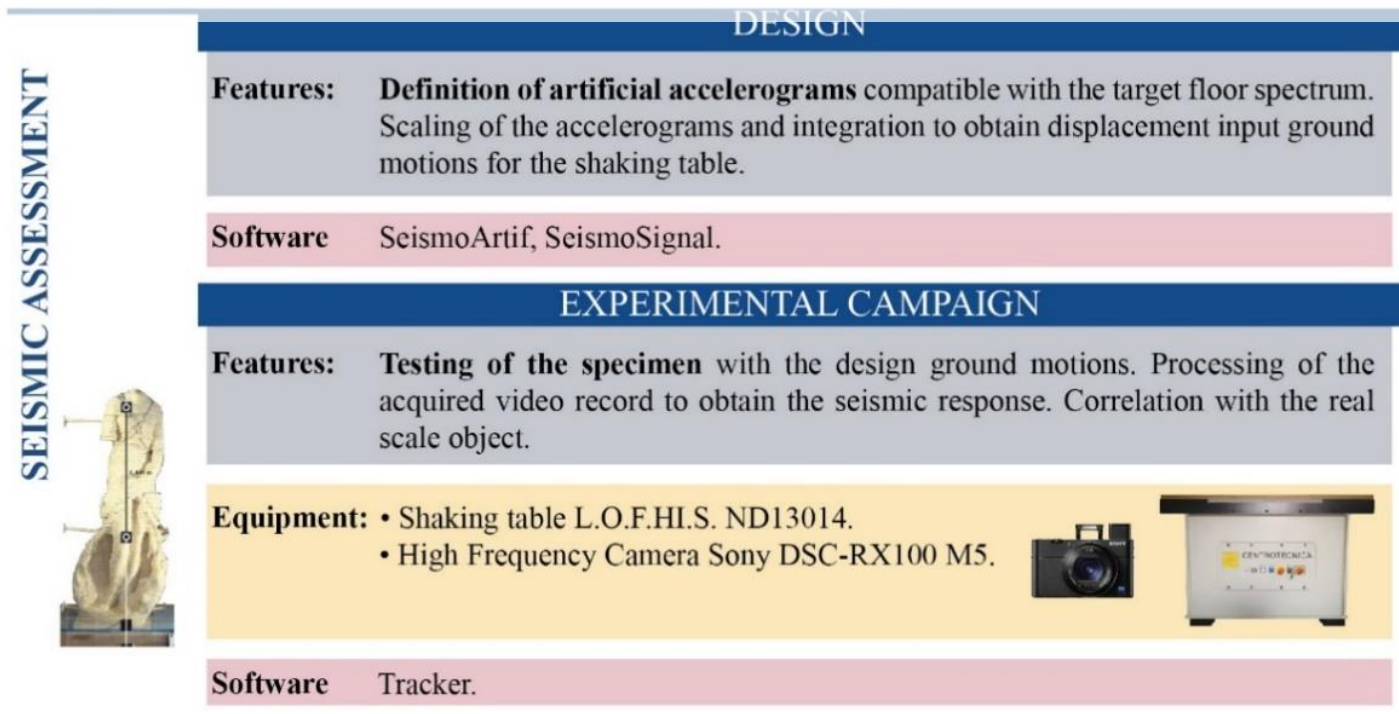

Figure 1: The proposed methodology. 

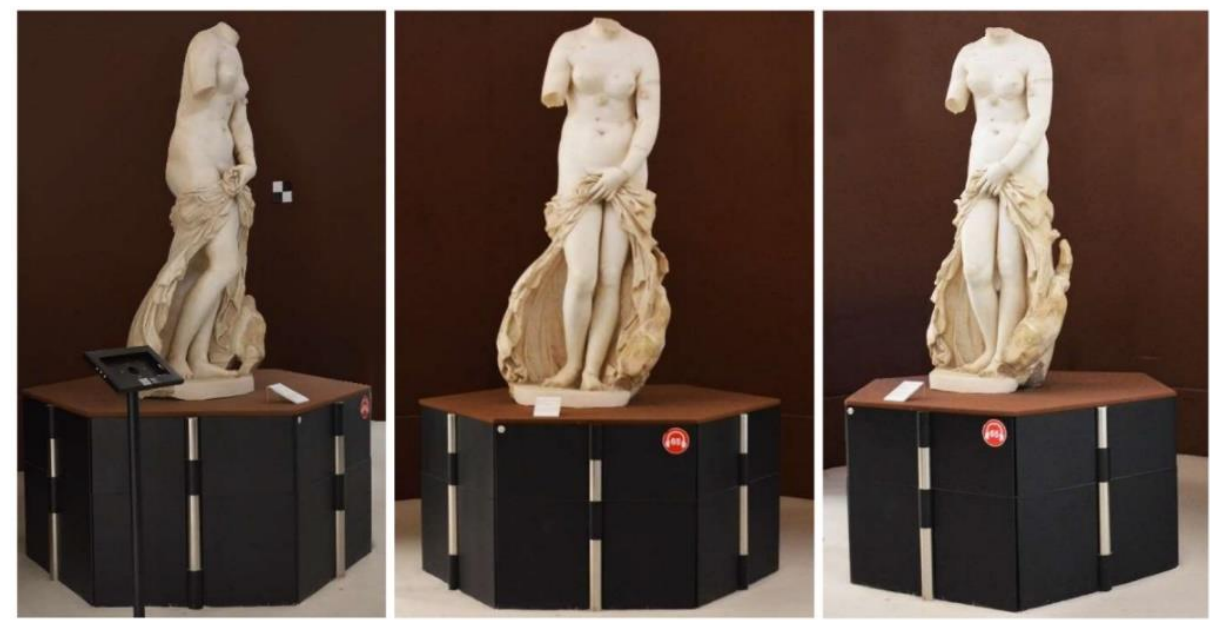

Figure 2: Venere Landolina

The methodological process of the 3D model production through a high precision mathematical representation of the object surface, provided the virtual development of the real artistic object.

The formal complexity of the examined sculpture suggested, as previous research [19], an integrated survey analysis obtained through the combination of range-based and image-based techniques. More specifically and SfM, Structure fron information, to visuliz architectural data.

From the operational instrumental survey campaign was
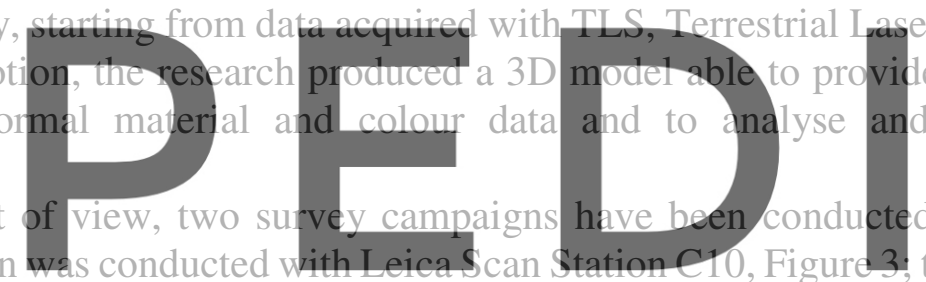
Scanner,
complex
interpret
: the first
he second photogrammetric survey was performed with digital camera and UAS technology, Figure 3.

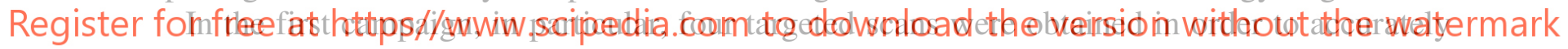
align the various digital images in the post processing phase through Cyclone Software.

In the second campaign various shots were taken at different heights turning around the sculpture.

SfM technique can produce a texturized 3D model starting from a set of digital shots. 3DF Zephyr Aerial can automatically process image features, all the visible key-points on different shots, creating correspondences for the image matching. The detected features were then computed in a 3D sparse point cloud and all the coordinates to the key-points of the surrounding items were optimized to generate a dense point cloud.

In order to acquire a greater amount of data, UAS technology has been introduced. It can produce high-resolution imagery which is almost impossible to obtain with traditional systems. In the specific case, a quadcopter DJI Spark weighing just 300 grams captured aerial imagery of the upper surface of the Venus.

This technology has aroused considerable interest in the scientific community and UAV, Unmanned Aerial Vehicles, are used in different fields of engineering, architecture and archaeology [20]-[23].

It generates, rapidly and at low cost, the necessary data for the production of precise models with the integration of vertical and oblique imagery. 
Alessia Di Martino, Giuseppe Cocuzza Avellino, Emanuela Paternò, Francesco Cannizzaro, Ivo Caliò,

Gianfranco Gianfriddo, Rita Valenti and Nicola Impollonia
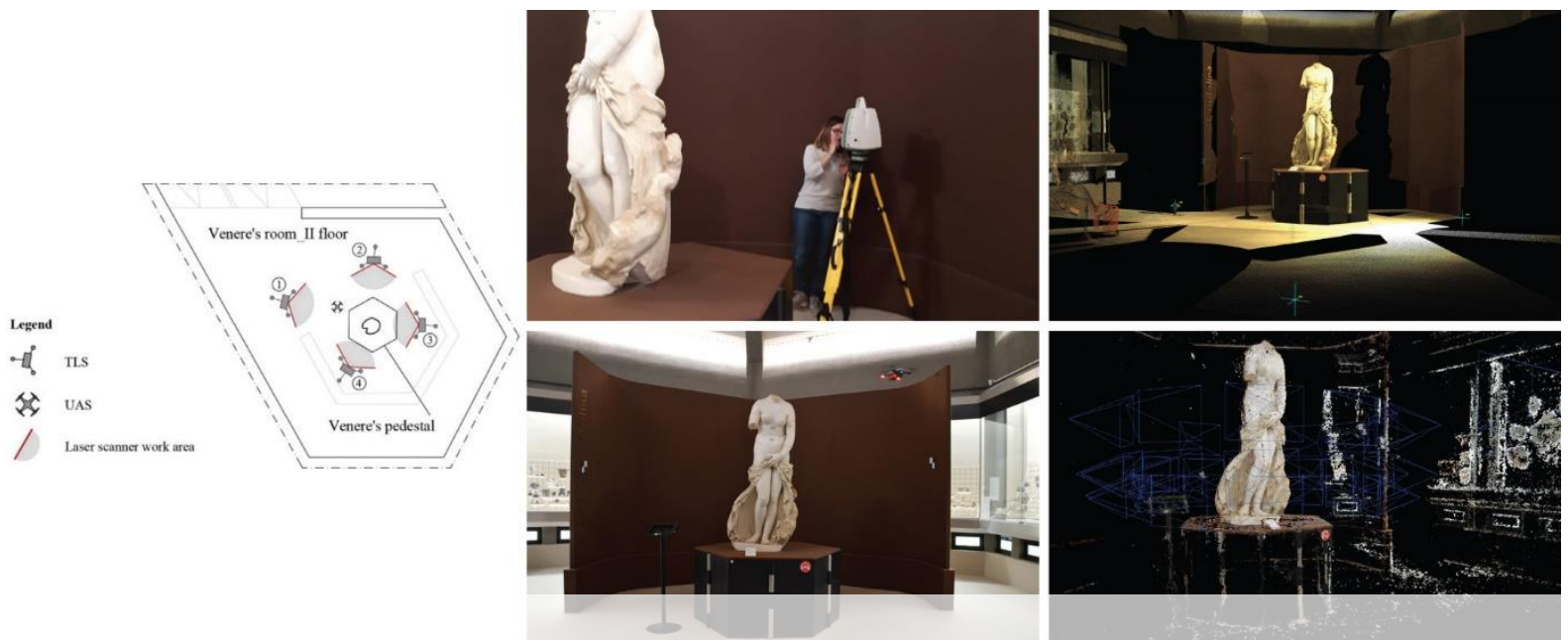

Figure 3: TLS and UAS technology

The point cloud obtained with instrumental survey was imported to 3DF Zephyr Aerial and the dense point cloud obtained from digital automatic photogrammetry was aligned to it. Such a model was then exploited to start the mesh generation and texture mesh generation in order to obtain a photorealistic 3D model.

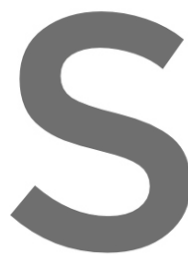

Finally, Geomagic Wrap performed long and patient retopology procedure in order optimise the polygonal model generated through the integration of the different techniques, Figure 4.

The last phase was extremely important to create the final printing of the model. The use of quick prototypization generated a single copy of the physical model exchusively designed for the study and the proposed research. For the correct interaction between the survey product and

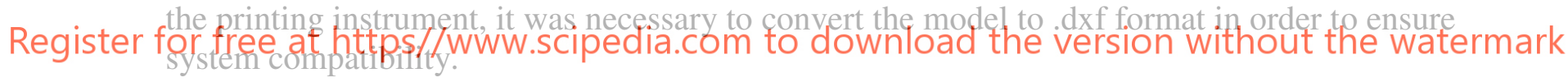

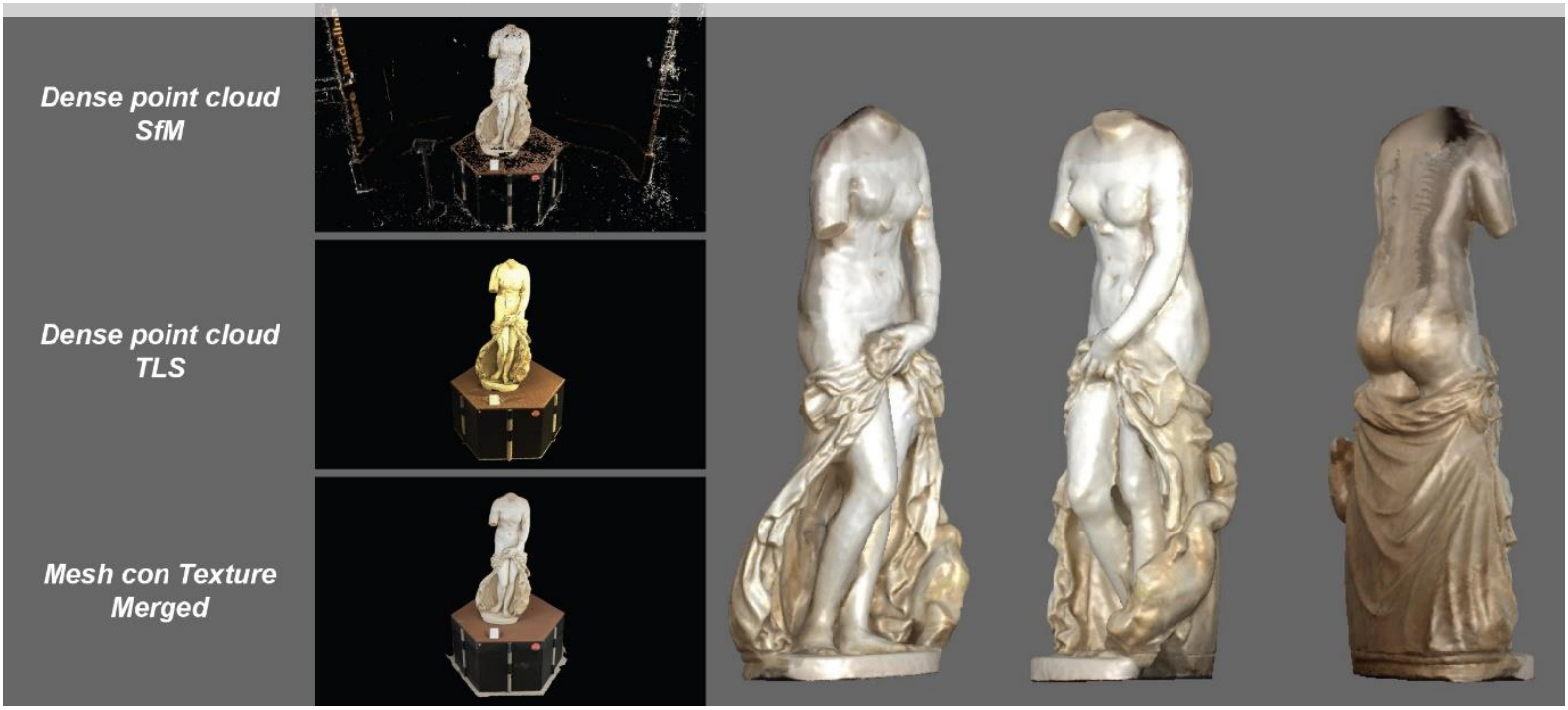

Figure 4: Elaboration of the 3D textured model 


\section{RECONSTRUCTION OF A WOODEN SCALED PHYSICAL MODEL}

The digital model arranged in the previous section has to be manipulated to generate proper input files to reconstruct a scaled and simplified physical model of the statue. In particular, a wooden specimen (with scale factor 1:2) is created by superimposing thick sections to each other obtained by flat OSB (Oriented Strand Board, a product made of glued wood shavings layers) $9 \mathrm{~mm}$ panels. To this purpose, the solid model is cut with equally spaced horizontal planes (with spacing equal to the thickness of the OSB panels), identifying the contour of each section; each of the considered horizontal section is approximatively considered representative of a certain thickness $(9 \mathrm{~mm})$, Figure 5a. It is worth to mention that the main difficulty in reproducing the actual behaviour of the statue results not from the complex geometry but to the complex interface between the statue and its support on which it can rock, wobble and slide. The real marble statue might have different properties from those associated to the woodden specimen; for this reason, additional tests will have to be performed considering different contact materials.

91 sections are considered in this case taking into account the additional thickness of the glue, and the corresponding contours represent the input for the $\mathrm{CNC}$ milling machine. The cuts were performed adopting a cutter with a diameter of $3 \mathrm{~mm}$ and 2 blades, considering a depth increment equal to $4,7 \mathrm{~mm}$, a cut velocity equal to $800 \mathrm{~m} / \mathrm{min}$ and a safety vertical distance equal to $12 \mathrm{~mm}$. The shaping of the 91 sections took 48 hours of worktime for the CNC machine, Figure 5b. In addition, each section is endowed with 2 (to 4) $10 \mathrm{~mm}$ holes intended

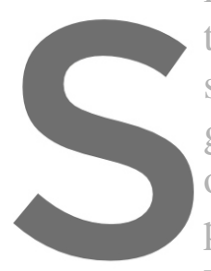
to allow the insertion of vertidal wooden bars
section is then refined sanding their border. The
glue hardening took 15 days. The final physic
of about $20257,897 \mathrm{~cm}^{3}$ and a weight of 12,073
position of the center of gravity is in relation to y) $,-14,0 \mathrm{~cm}$ (dir. z), Figure 6. Such edges have
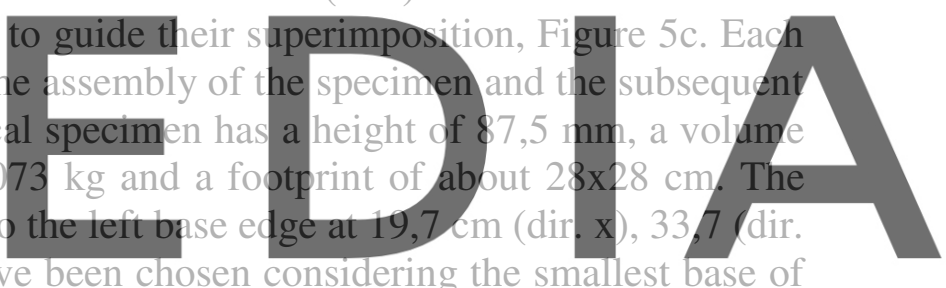
the statue: however for a comprehensive study additional experimental tests considering

The simplified scaled digital model of the statue depicted in Figure 5a-d allowed to easily identify some geometric features of the specimen, as shown in Figure 6 where the adopted reference system is also identified. As better shown in the next section, the specimen will be subjected to ground motions through a single degree of freedom shaking table. The two edges around which the specimen can rotate are identified as 1 and 2, and the relevant geometrical moments of inertia around the edges are equal to $I_{1}=4,2808 \times 10^{7} \mathrm{~cm}^{5}$ and $I_{2}=3,6318 \times 10^{7}$ $\mathrm{cm}^{5}$, respectively. The critical angles which may lead the statue to the overturning are $\delta_{1}=$ $30,31^{\circ}$ and $\delta_{2}=13,84^{\circ}$ in the negative and positive directions, respectively.

\section{THE EXPERIMENTAL CAMPAIGN}

Aiming to a proper seismic assessment of the statue, the scaled wooden specimen was subjected to shaking table tests considering different ground motions. The experimental setup includes a single degree of freedom shaking table (from the LO.F.HI.S. series ND13014 (Low Frequency High Stroke and Velocity Shaker) and a high frequency acquisition camera (DSRX100 M5) for contactless displacement data acquisition. To this purpose, the video records are processed using the Tracker Video Analysis and Modeling Tool software ver. 5.0.7" [24]. 
Alessia Di Martino, Giuseppe Cocuzza Avellino, Emanuela Paternò, Francesco Cannizzaro, Ivo Caliò,

Gianfranco Gianfriddo, Rita Valenti and Nicola Impollonia

Details on the experimental setup, on the contactless data acquisition and the subsequent data processing can be found in [11].
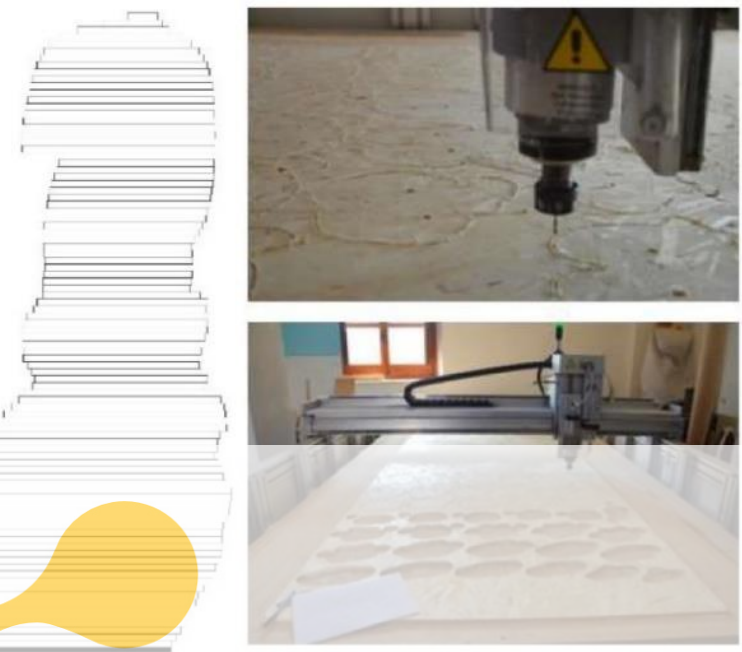

(b)

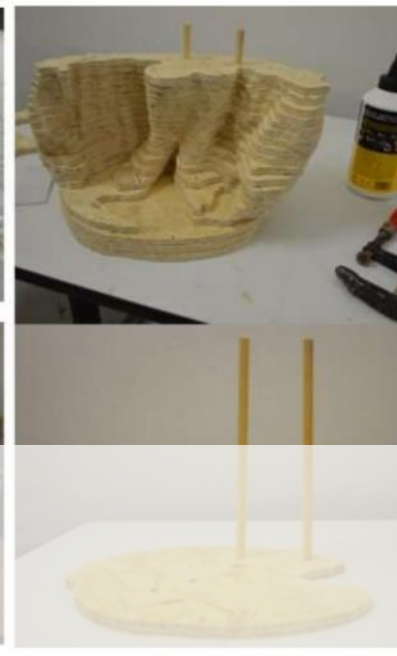

(c)

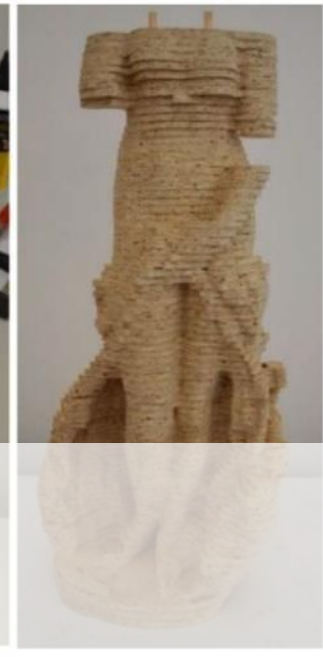

(d)

Figure 5: Wooden scaled specimen: (a) simplified digital model, (b) CNC machine, (c) superimposition of the sections, and (d) near-final result.
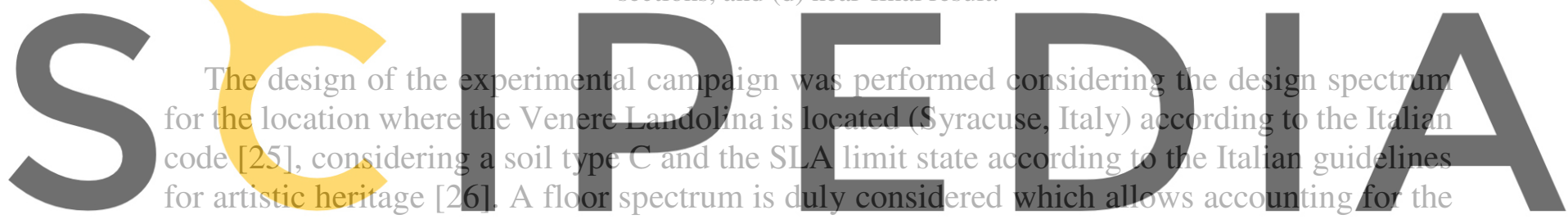

location of the statue inside the museum (second of three levels with equal interstorey).

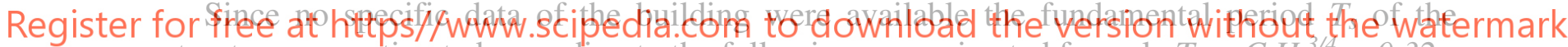
structure was estimated according to the following approximated formula $T_{s}=\mathrm{CH}^{3 / 4}=0.32 \mathrm{~s}$

In Figure 7 the adopted design spectrum is depicted, together with the main data for its definition.
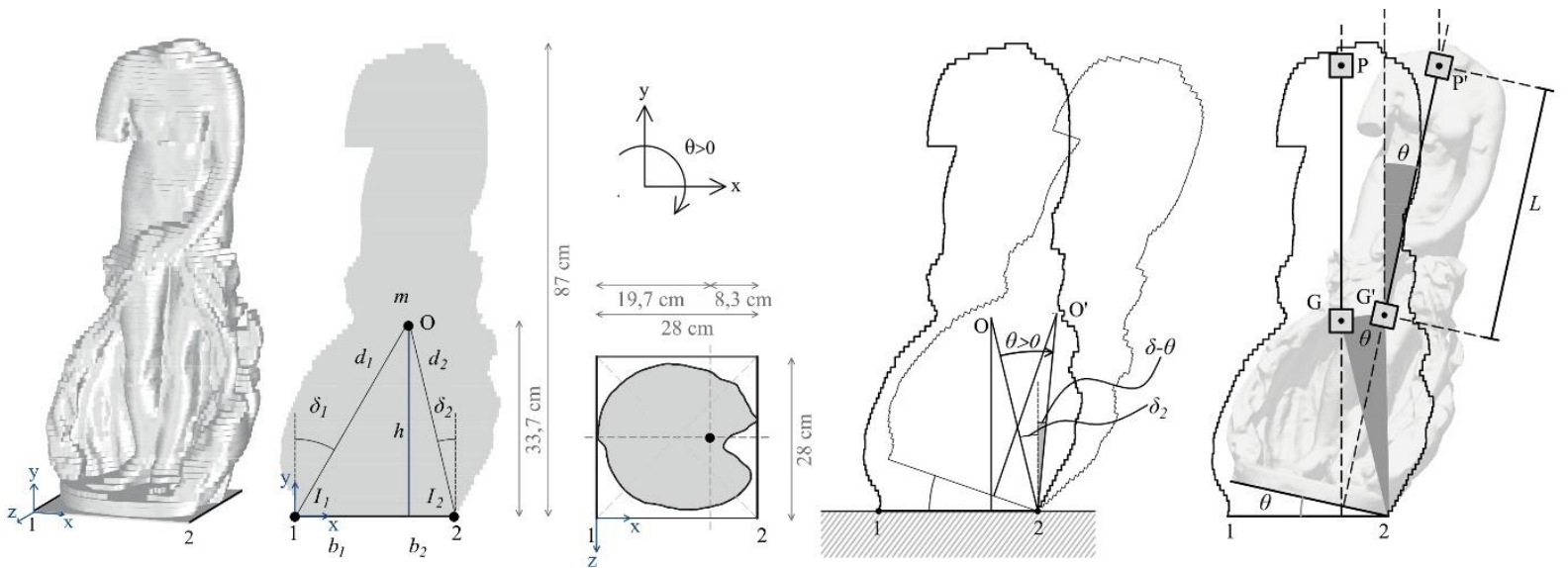

Figure 6: Main geometric features of the wooden specimen and adopted kinematic model and markers layout 
Seven artificial spectrum-compatible accelerograms were then generated through the software SeismArtif [27]. Since the scale factor $\lambda$ of the specimen with respect to the actual statue is equal to 2 , in order to obtain the ground motion to be applied to the shaking table, the time axis was scaled by a factor $\lambda^{0.5}$, according to the Froude analogy [28]. One of the generated accelerograms is reported in Figure 8 (light grey) together with the corresponding scaled one (black); in the same Figure the theoretical (dashed lines) and experimental (dashdot lines) uplift accelerations (for both side) are also reported. The spectrum compatibility of the generated accelerograms is duly verified, Figure 7; then, the scaled accelerograms are integrated twice thus defining the input ground motions to be applied to the specimen with the shaking table.

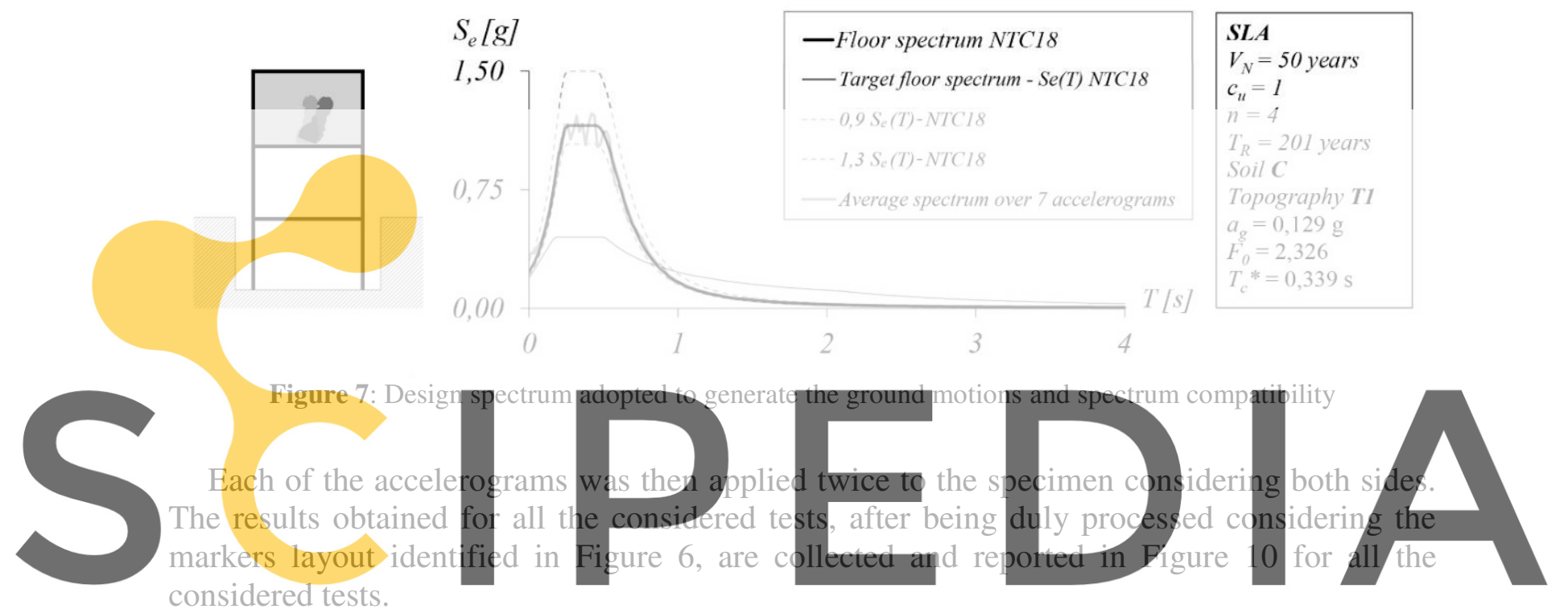

Register for free at https//www.scipedia.com to download the version without the watermark

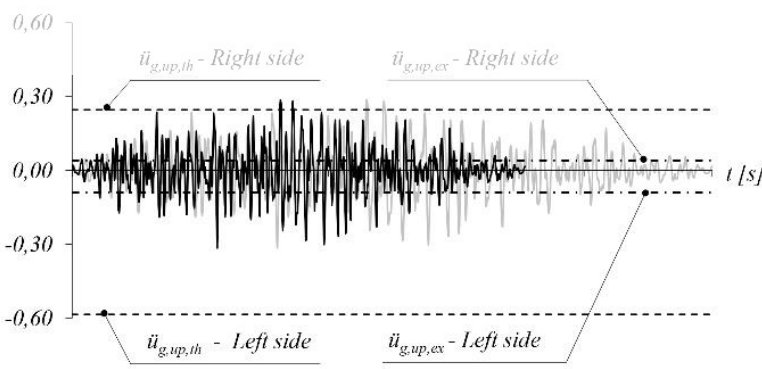

(a)

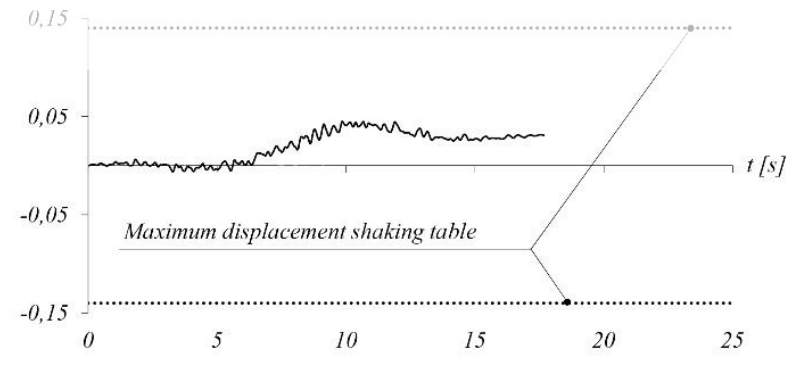

(b)

Figure 8: Design of the experimental campaign: (a) artificial accelerogram and corresponding scaled one, (b) input ground motion for the shaking table.

The obtained results show that, as expected, the specimen uplifts for all the considered ground motions (the normalized Peak Ground Acceleration is greater than the ratio $b_{i} / h$, $i=1, \ldots, 4)$; however, no overturning is observed. The obtained responses in terms of rotation angle $\theta$, normalized by the minimum critical angle $\delta_{2}$, show that the specimen tends to a more pronounced rocking around the edge 2 . The average maximum angle over the seven ground 
motions for the positive and negative directions are $\theta_{a v_{-} \max , 1}=8,26^{\circ}$ and $\theta_{a v_{-} \max , 2}=24,82^{\circ}$, respectively; the corresponding absolute values are $\theta_{a b_{-} \max , 1}=12,30^{\circ}$ (observed for the $5^{\text {th }}$ accelerogram ${ }^{+}$) and $\theta_{a b_{-} \max , 2}=47,26^{\circ}$ (observed for the $1^{\text {st }}$ accelerogram $\left.{ }^{-}\right)$, respectively, which are those reported in Figure 9.
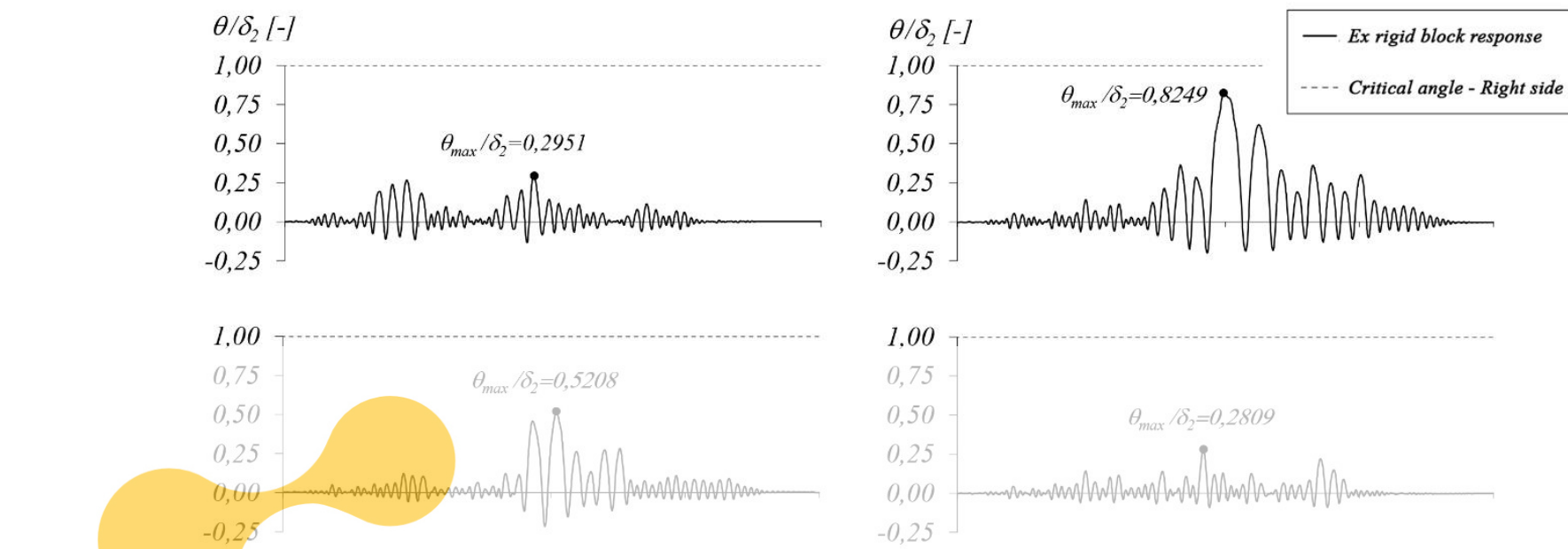

Figure 9: Normalized angle response vs time: (a) positive and (b) negative ground motions
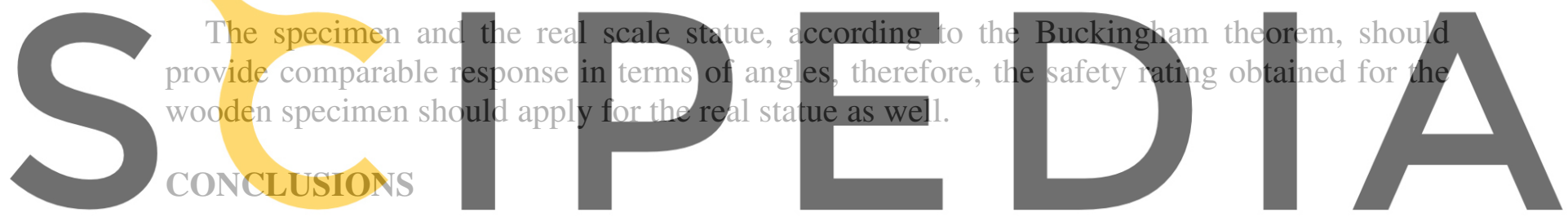

In this paper a novel interdisciplinary methodology to experimentally assess the

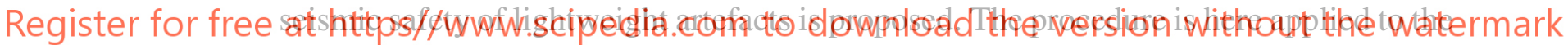

Venere Landolina statue, preserved in Paolo Orsi museum in Siracusa (Italy).

The proposed strategy involves the construction of a scaled wooden specimen based on a digital model obtained by means of a laser scanner non-invasive relief and photogrammetry survey using UAS and TLS technologies.

- After processing and scaling the 3D digital model, the physical model is obtained through superimposition of wooden thick sections, properly shaped by means of a Computer Numerical Control machine.

- $\quad$ The specimen is then tested on a single degree of freedom shaking table, considering seven artificial spectrum-compatible ground motion, duly modified to account for the scale factor of the specimen with respect to the real statue. Specific guidelines for artistic heritage are employed to generate the accelerograms.

- $\quad$ The obtained results show a limited variability of the specimen response to the different inputs, and a substantial safety of the statue with respect to the design earthquake. As expected, the different properties of the specimen with respect to the load directions imply a strong asymmetry with respect to the uplift side.

- The proposed methodology, which involves several disciplines, has the great advantage to allow conducting experimental tests (through the construction of a 
faithful physical model) on objects of priceless value. The original artefact does not undergo any direct contact and does not need to be moved to capture its geometry. Objects with complex geometry can be handled without loss of generality. The obtained results show the applicability of the proposed geometry on a larger scale.

Acknowledgements. The authors gratefully thank the management of the "Paolo Orsi" museum, in particular Dr. Maria Musumeci, for her sensitivity toward the seismic protection of the museum content and for the authorization to carry out the survey of the "Venere Landolina". This research was partially supported by the research project "eWAS - A nearly warning system for cultural heritage".

\section{REFERENCES}

[1] Borri, A. and Grazini, A. Diagnostic analysis of the lesions and stability of Michelangelo's David. Journal of Cultural Heritage (2006) 7:273-285.

[2] Cerri, G., Pirazzoli, G., Tanganelli, M., Verdiani, G., Rotunno, T., Pintucchi, B. and Viti, S. Seismic Assessment of Artefacts: The Case of Juno's Fountain of the National Museum of Bargello. IOP Conference Series: Materials Science and Engineering (2018) 364, 012057.

[3] Housner, G.W. The behavior of inverted pendulum structures during earthquakes. Bull. Seismo. Soc. Am. (1963) 53:404-417.

[4] Aslam, M., Godden, W. G. and Scalise, D. T. Earthquake Rocking Response of Rigid Bodies (1978) Lawrence Berkley Laboratory.

[5] Giannini, R., Giuffre, A. and Masiani, R. La dinamica delle strutture composte di blocchi sovrapposti: studi in corso sulla colonna Antoniana, VIII Congresso nazionale dell'Associazione Italiana di meccanica Teorica ed Applicata, 1986, Turin, Italy 29September - 3 October, 1:299-304.

[6] Spanos, P.D., Di Matteo, A., Pirrotta, A. and Di Paola, M. Nonlinear rocking of rigid blocks on flexible foundation: analysis and experiments. Procedia Engineering (2017) 199:284289.

[7] Ioannis, N., Psycharis, N. and Jennings, P.C. Upthrow of objects due to horizontal impulse excitation, Bulletin of the Seismological Society of America (1985) 75(2):543-561.

[8] Chatzis, M.N., and Smyth, A.W. Robust Modeling of the Rocking Problem. Journal of Engineering Mechanics (2012) 138(3) 247-262.

[9] Spanos, P.D. and Koh, A.S. Rocking of rigid blocks due to harmonic shaking. Journal of Engineering Mechanics (1984) 110(11):1627-1642.

[10] Shenton III, H.W. and Jones, N.P. Base excitation of rigid bodies. I: formulation. Journal of Engineering Mechanics (1991) 117(10):2286-2306.

[11] Cocuzza Avellino, G., Caliò, I., Cannizzaro, F., Caddemi, S. and Impollonia, N. Response spectra of rigid blocks with uncertain behaviour. COMPDYN 2019 7th ECCOMAS Thematic Conference on Computational Methods in Structural Dynamics and Earthquake Engineering M. Papadrakakis, M. Fragiadakis (eds.) Crete, Greece, 24-26 June 2019.

[12] Jeong, M.Y., Lee, H., Kim, J.H. and Yang, I.Y. Chaotic behavior on rocking vibration of rig-id body block structure under two-dimensional sinusoidal excitation (in the case of no sliding). KSME International Journal (2003) 17(9):1249-1260. 
[13] Di Egidio, A., and Contento, A. Seismic response of a non-symmetric rigid block on a constrained oscillating base. Engineering Structures (2010) 32:3028-3039.

[14] De Canio G. Basi antisismiche in marmo per i Bronzi di Riace. Archeomatica (2011) 2(1).

[15] Caliò, I. and Marletta, M. Passive control of the seismic rocking response of art objects, Engineering Structures (2003) 25:1009-1018.

[16] Donà, M., Hugh Muhr, A., Tecchio, G. and da Porto, F. Experimental characterization, design and modelling of the RBRLseismic-isolation system for lightweight structures. Earthquake Engng Struct. Dyn (2017) 46:831-853.

[17] Podany, J. An Overview of Seismic Damage Mitigation for Museums. International Symposium on Advances of Protection Devices for Museum Exhibits, April 13-17, 2015 Beijing and Shanghai China.

[18] Valenti, R., Paternò E., 2017. The Itineraries of Drawing: from museum works to art places. In: Territories and frontiers of representation, p. 1307-1314, Roma:Gangemi Editore, ISBN: 978-88-492-3507-4

[19] Valenti, R., Paternò E., 2020. Imagined spaces in church architectural furnishings: Solomon's temple in small scale architectural language. In: Advances in Utopian Studies and Sacred Architecture, Cham: Springer, in press.

[20] Remondino, F., Barazzetti, L., Nex, F., Scaioni, M., Sarazzi, D., 2011. UAV photogrammetry for mapping and $3 \mathrm{~d}$ modeling -current status and future perspectives -. In: ISPRS International Archives of the Photogrammetry, Remote Sensing and Spatial $\begin{array}{llll}\text { Information } \quad \text { Sciences, } & \text { Volume } & \text { XXXVIII-1, } & \text { pp. }\end{array}$ https://doi.org/10.5194/isprsarchives-XXXVIII-1-C22-25-2011

[21] Bolognesi, M., Furini, A., Russo, V., Pellegrinelli, A., Russo, P., 2014. Accuracy of cultural heritage 3D models by RPAS and terrestrial photogrammetry. In: ISPRS International Archives of the Photogrammetry, Remote Sensing and Spatial Information Sciences, Volume XL-5, pp. 113-119

[22] Aicardi, I., Chiabrando, F., Grasso, N., Lingua, A. M., Noardo, F., Spanò, A. T., 2016. UAV photogrammetry with oblique images: First analysis on data acquisition and processing. In: ISPRS-International Archives of the Photogrammetry, Remote Sensing and Spatial Information Sciences, Volume XLI, pp. 835-842

[23] Carnevali, L., Ippoliti, E., Lanfranchi, F., Menconero, S., Russo, M., Russo, V., 2018. Close-range mini-UAVs photogrammetry for architecture survey. In: ISPRS International Archives of the Photogrammetry, Remote Sensing and Spatial Information Sciences, Volume XLII-2, pp. 217-224

[24] D. Brown, C. Wolfgang, Simulating what you see: combining computer modeling with video analysis, MPTL 16 - HSCI 2011, Ljubljana 15 -17 September 2011.

[25] Ministero delle infrastrutture e dei trasporti, Decreto 17 gennaio 2018, Aggiornamento delle "Norme tecniche per le costruzioni" - NTC18

[26] Linee guida per la valutazione e la riduzione del rischio sismico del patrimonio culturale con riferimento alle Norme tecniche per le costruzioni di cui al decreto del Ministero delle Infrastrutture e dei trasporti del 14 gennaio 2008

[27] Seismosoft 2020 "SeismoArtif - A computer program for generation of artificial accelerograms". Available from URL: www.seismosoft.com.

[28] Sandro Longo, Analisi dimensionale e modellistica fisica. Principi e applicazioni alle scienze ingegneristiche, Springer-Verlag, Italia 2011 